\title{
Porfirias: quadro clínico, diagnóstico e tratamento
}

\section{Porphyrias: clinical presentation, diagnosis and treatment}

\author{
Carla Luana Dinardo', Guilherme Henrique Hencklain Fonseca², \\ Liliana Mitie Suganuma ${ }^{3}$, Sandra Fátima Menosi Gualandro ${ }^{3}$, \\ Dalton de Alencar Fischer Chamone ${ }^{5}$
}

\begin{abstract}
Dinardo CL, Fonseca GHH, Suganuma LM, Gualandro SFM, Chamone DAF. Porfirias: quadro clínico, diagnóstico e tratamento. Rev Med (São Paulo). 2010 abr.-jun.;89(2):106-14.

RESUMO: As porfirias são doenças incomuns e de herança genética na maior parte dos casos. As porfirias são divididas em eritropoiéticas, hepáticas agudas e hepáticas crônicas. Os subtipos de maior relevância clínica são a porfiria cutânea tarda e a porfiria intermitente aguda. O diagnóstico das porfirias pode ser bastante difícil, dada a sobreposição de quadros clínicos e achados bioquímicos. A precisão do diagnóstico depende da dosagem de porfirinas urinárias e fecais, da análise da atividade enzimática de eritrócitos e, eventualmente, da pesquisa de mutações. O objetivo do presente artigo é realizar revisão literária das porfirias, com ênfase no diagnóstico e tratamento de seus diversos subtipos.
\end{abstract}

DESCRITORES: Porfirias/diagnóstico; Porfiria aguda intermitente/diagnóstico; Porfiria cutânea tardia/diagnóstico.

\section{INTRODUÇÃO}

Dorfirias decorrem de deficiências enzimáticas na biossíntese do grupo heme da cadeia da hemoglobina. Na maior parte das vezes, são distúrbios hereditários, embora existam formas adquiridas. As porfirias apresentam ampla interação entre fatores genéticos e fatores ambientais, pois os portadores de mutações nem sempre desenvolvem a doença na ausência de fatores ambientais precipitantes.

Biossíntese do heme
A biossíntese do grupo heme ocorre em todas as células nucleadas dotadas de mitocôndrias. Há predominância do processo em células de linhagem eritropoiética, em que haverá a síntese de hemoglobina e em células hepáticas, em que haverá síntese de enzimas como a citocromo p450, a catalase, a triptofan-pirrolase e citocromo oxidase ${ }^{1}$.

A primeira fase da biossíntese do heme ocorre na mitocôndria; as quatro fases intermediárias ocorrem no citosol e, finalmente, as três fases finais ocorrem novamente na mitocôndria (Figura 1).

\footnotetext{
1. Médica do Serviço de Hematologia e Hemoterapia. Departamento de Hematologia e Hemoterapia do Hospital das Clínicas da Faculdade de Medicina da Universidade de São Paulo.

2. Médico do Serviço de Hematologia e Hemoterapia. Departamento de Hematologia e Hemoterapia do Hospital das Clínicas da Faculdade de Medicina da Universidade de São Paulo.

3. Médica do Serviço de Hematologia e Hemoterapia. Departamento de Hematologia e Hemoterapia do Hospital das Clínicas da Faculdade de Medicina da Universidade de São Paulo.

4. Professor Titular do Serviço de Hematologia e Hemoterapia. Departamento de Hematologia e Hemoterapia do Hospital das Clínicas da Faculdade de Medicina da Universidade de São Paulo.

Endereço para correspondência: Carla Luana Dinardo. Rua Girassol, 1263 apto 82 - CEP 05433-002, São Paulo, SP, e-mail: carlaluana@yahoo.com.br
} 


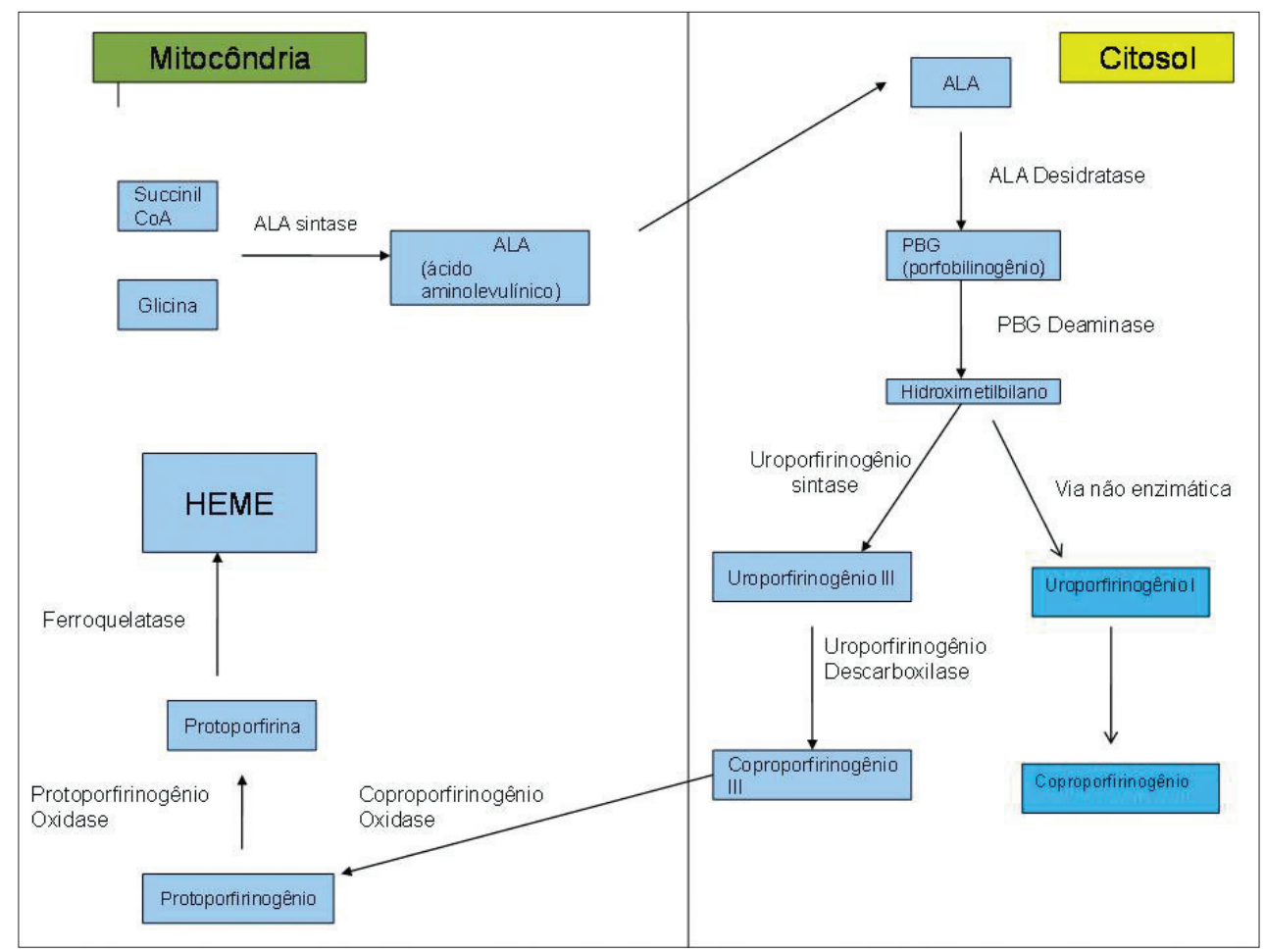

FIGURA 1: A biossíntese de heme tem início quando uma molécula de succinil-CoA, em conjunto com uma glicina, sob ação da enzima ALA sintase, dão origem ao ácido aminolevulínico (ALA). Duas moléculas de ácido aminolevulínico, no citosol, são condensadas pela enzima ALA desidratase, dando origem ao porfobilinogênio (PBG). Quatro moléculas de PBG são convertidas a hidroxometilbilano pela enzima PBG deaminase. O hidroximetilbilano pode ser convertido a uroporfirinogênio III, através da uroporfirinogênio sintase, ou a uroporfirinogênio I, através de via não enzimática. O uroporfirinogênio III é descarboxilado a coproporfirinogênio III através da uroporfirinogênio descarboxilase e a uroporfirinogênio I é, por sua vez, convertida a coproporfirinogênio I, o qual não é intermediário para a bissíntese do heme. O corpoporfirinogênio III, através da coproporfirinogênio oxidade, é transformada em protoporfirinogênio IX, a qual é convertida a protoporfirina IX pela protoporfirinogênio oxidase. Finalmente, o ferro é inserido na molécula de protoporfirina IX, através da ação da ferroquelatase, dando origem ao heme ${ }^{1}$

O processo de biossíntese do heme é regulado por vários fatores, sendo que o principal deles se dá na fase da ALA sintase ${ }^{2}$. Tal regulação decorre da presença de dois tipos de ALA sintase: a tipo 1, que é expressa em tecido hepático e é suprimida pela presença do heme, e a tipo 2 , que é expressa em tecido eritropoiético e estimulada na presença de ferro intracelular.

\section{Considerações gerais}

Todos os intermediários da biossíntese do heme são potencialmente tóxicos. A sintomatologia decorrente engloba sintomas cutâneos, decorrentes do acúmulo de porfirinas nas camadas mais superficiais da pele, e sintomas neuroviscerais, relacionados ao acúmulo de ALA e PBG.

Para o diagnóstico de porfiria, é necessária a dosagem das profirinas nas fezes e na urina. A solubilidade na água destes intermediários determina sua forma de excreção: produtos solúveis em água são excretados na urina, produtos insolúveis em água são excretados nas fezes e produtos com solubilidade intermediária são excretados tanto na urina quanto nas fezes. A Tabela 1 mostra os diferentes intermediários do heme e seus padrões de excreção.

TABELA 1: Solubilidade dos intermediários da biossíntese do heme

\begin{tabular}{l|l|l}
\hline Uroporfirina & Solúvel em água & Urinária \\
\hline Protoprofirina & Insolúvel em água & Fecal \\
\hline Coproporfirina & $\begin{array}{l}\text { Solubilidade } \\
\text { intermediária }\end{array}$ & Ambas \\
\hline ALA e PBG & Solúveis em água & Urinária \\
\hline
\end{tabular}

\section{Classificação das porfirias}

Classicamente as porfirias são divididas em eritropoiéticas e hepáticas, dependendo de onde predomine a deficiência enzimática (Tabela 2). 
Dinardo Cl, et al. Porfirias: quadro clínico, diagnóstico e tratamento.

TABELA 2: Porfirias eritropoiéticas englobam a porfiria eritropoiética congênita e a protoporfiria eritropoiética

\begin{tabular}{l|l|l}
\hline \multirow{2}{*}{ Porfirias crônicas } & Porfirias eritropoiéticas & $\begin{array}{l}\text { Porfiria eritropoiética congênita } \\
\text { Protoporfiria eritropoiética }\end{array}$ \\
\cline { 2 - 3 } & Porfirias hepáticas crônicas & Porfiria cutânea tarda \\
\hline Porfirias agudas & Porfirias hepáticas agudas & $\begin{array}{l}\text { Porfiria por deficiência da ALA desidratase } \\
\text { Porfiria intermitente aguda } \\
\text { Coproporfiria hereditária } \\
\text { Porfiria variegata }\end{array}$ \\
\hline
\end{tabular}

As porfirias hepáticas são, por sua vez, subdivididas em hepáticas agudas e crônicas, sendo que a primeira engloba a porfiria por deficiência da ALA desidratase, a porfiria intermitente aguda, a coproporfiria hereditária e a porfiria variegata, e a segunda, a porfiria cutânea tarda e a porfiria hepatoeritropoiética Mais recentemente, as porfirias foram divididas em agudas e crônicas. As porfirias agudas englobam o grupo das hepáticas agudas, enquanto que as porfirias crônicas englobam tanto as porfirias eritropoiéticas quanto as hepáticas crônicas ${ }^{1}$.

\section{porfirias}

\section{Quadro clínico e laboratorial das}

\section{Porfirias eritropoiéticas}

(a) Porfiria Eritropoiética Congênita (PEC)

Primeira porfiria descrita, no ano de 1874. Trata-se de transtorno autossômico recessivo caracterizado pela deficiência quase completa da uroporfirinogênio sintase. Como consequência da deficiência enzimática, há acúmulo dos isômeros do tipo I (uroporfirinogênio e coproporfirinogênio).

O quadro clínico é caracterizado por sintomas cutâneos e hematológicos. Do ponto de vista hematológico, há hemólise de leve a moderada, levando a anemia e a esplenomegalia secundária. O quadro cutâneo é caracterizado por friabilidade cutânea e formação de bolhas nas áreas fotoexpostas (sobretudo mãos e face). Há infecções cutâneas secundárias de repetição e cicatrização exacerbada, podendo levar à perda de dígitos ${ }^{1}$.

Outros sintomas presentes são: urina rosada ou avermelhada (pelo acúmulo de porfirinas), hipertricose de face e extremidades e eritrodontia, que corresponde à coloração avermelhada de dentes quando expostos à radiação de $400 \mathrm{~nm}$. Podem ocorrer alterações significativas de arcabouço ósseo, decorrentes tanto da expansão medular secundária à anemia quanto da deficiência de vitamina D. Cegueira pode ser decorrente de cicatrizes lenticulares e lesão hepática que, apesar de incomum, também pode estar presente.

Laboratorialmente, há excreção urinária de porfirinas notoriamente elevada (50-100mg/d). Esta é composta, basicamente, por uroporfirinogênio I, coproporfirinogênio I e 7-carboxil porfirina. As porfirinas fecais também são elevadas à custa de coproporfirinogênio $\mathrm{I}^{3}$.

(b) Protoporfiria Eritropoiética (PPE)

Distúrbio autossômico dominante com penetrância incompleta, comum em asiáticos. Decorre da deficiência parcial da ferroquelatase.

Clinicamente, a doença caracteriza-se por fotossensibilidade desde a infância, atingindo principalmente face e dorso das mãos e apresentandose como áreas de eritema e edema difusos, com sensação de queimação local ${ }^{4}$. Um dos principais diagnósticos diferenciais é com o edema angioneurótico. A insuficiência hepática não é incomum, decorre do depósito de propoporfirina que é tóxico ao fígado. Podem ainda ser encontrados: colelitíase, anemia microcítica leve e sideroblatos em anel ${ }^{1}$.

Laboratorialmente, há aumento de protoporfirina nos eritrócitos, no plasma e nas fezes, mas não na urina. Os precursores eritróides ricos em protoporfirina mostram intensa fluorescência sob a luz de $405 \mathrm{~nm}$ e são denominados fluorócitos. Tais células podem ser visualizadas por métodos manuais automatizados, contribuindo para a confirmação diagnóstica de protoporfiria eritropoiética ${ }^{5}$.

\section{Porfirias hepáticas crônicas}

(a) Porfiria Cutânea Tarda (PCT)

É a porfiria mais comum. Causada pela deficiência da uroporfirinogênio descarboxilase, por mutação heterozigótica. Há três subtipos principais: tipo I, que apresenta atividade da uroporfirinogênio descarboxilase normal em eritrócitos e casos esporádicos; tipo II, que apresenta atividade 
eritrocitária enzimática reduzida e casos familiares; e a tipo III, que apresenta casos familiares e atividade eritrocitária enzimática normal.

O quadro clínico é caracterizado por lesões bolhosas crônicas em áreas fotoexpostas. Locais previamente acometidos pelas lesões cutâneas podem se apresentar atróficos ou com pseudoesclerodermia. Podem ocorrer hipertricose e hiperpigmentação e, em casos graves, fotomutilação, sobretudo se houver infecções de repetição. É também característica clínica muito importante a presença de hemossiderose hepática, que é reflexo da sobrecarga de ferro presente nos pacientes (saturação de ferro e ferritina aumentados) 6 .

A maior parte dos portadores da mutação do gene da uroporfirinogênio descarboxilase nunca desenvolve a porfiria cutânea tarda. Aqueles que manifestam a doença o fazem após exposição a alguns desencadeadores ambientais. Dentre estes, destacam-se: álcool, infecção pelo vírus da hepatite $\mathrm{C}$, exposição a estrógenos, infecção pelo HIV, hemodiálise, tumores hepáticos malignos ou benignos, fatores que aumentam o conteúdo do ferro no organismo (ex. mutação do gene HFE) e uso do mesilato de imatinibe $7,8,9,10$.

Laboratorialmente, observa-se aumento urinário de uroporfirinogênio e hepta carboxil porfirina. Nas fezes, a presença de isocoproporfirina é característica da doença ${ }^{1}$.

(b) Porfiria hepatoeritropoiética

Trata-se de forma rara de porfiria, de herança autossômica recessiva. Caracteriza-se pela deficiência de uroporfirinogênio descarboxilase, por mutação homozigótica ou dupla heterozigótica.

Clinicamente, a doença é bastante semelhante à porfiria eritropoiética congênita, sendo caracterizada por lesões bolhosas cutâneas, hipertricose e cicatrizes cutâneas, urina rosa ou avermelhada, anemia hemolítica e esplenomegalia.

Laboratorialmente, é similar à porfiria cutânea tarda, ambas caracterizadas por excreção urinária de uroporfirinogênio e heptacarboxil porfirina e excreção fecal de isocoproporfirina. Há, ainda, aumento de protoporfirina eritrocitária ligada ao zinco'1.

\section{Porfirias hepáticas agudas}

Neste grupo de porfirias, $80 \%$ dos carreadores da mutação genética são assintomáticos.

As porfirias hepáticas agudas são caracterizadas por sintomas neuroviscerais. Para explicar tal fenômeno, diversas teorias já foram aventadas, dentre as quais se destacam:

1-Excesso de ALA e PBG é neurotóxico ${ }^{11}$;
2-Excesso de ALA inibe a liberação do ácido gamabutírico ${ }^{12}$.

3-Deficiência de heme resulta em alterações degenerativas do $\mathrm{SNC}^{13}$;

4-Redução do heme resulta em redução da triptofano pirrolase, levando a aumento dos níveis de triptofano cerebral e, consequentemente, aumento do turnover da 5 -hidroxitriptamina ${ }^{14}$.

(a) Porfiria Intermitente Aguda (PIA)

Distúrbio autossômico dominante caracterizado pela deficiência da enzima PBG deaminase. A prevalência da doença, nos EUA, é de 5-10 casos/100.000 habitantes.

A porfiria intermitente aguda é rara em crianças, sendo mais comum após a puberdade. É também quatro vezes mais comum em mulheres do que em homens. Caracteriza-se, clinicamente, pela ocorrência de ataques de dor abdominal, tetraparesia flácida e sintomas neuropsiquiátricos ${ }^{15,17}$. Manifestase, geralmente, após o contato com desencadeantes ambientais. Os ataques têm duração entre horas a dias e mortalidade em torno de $14 \%{ }^{15,16}$.

A dor abdominal é muito importante; geralmente tem caráter de cólica e ocorre em baixo ventre, justificando várias laparotomias exploradoras brancas. Ela pode ser acompanhada por taquicardia, hipertensão, constipação e retenção urinária aguda ${ }^{15}$.

Os sintomas neuropsiquiátricos são múltiplos: ansiedade, depressão, insônia, desorientação, alucinações, confusão, psicose, crises convulsivas e acometimento de pares cranianos. É importante ressaltar que a ocorrência dos sintomas psiquiátricos pode permanecer entre os ataques ${ }^{15}$.

A tetraparesia flácida é caracterizada por perda de força muscular e de sensibilidade, acometendo tanto musculatura proximal quanto distal $^{15}$.

Além desses sintomas, os pacientes podem apresentar anormalidades eletrolíticas (hiponatremia, por exemplo), devido tanto à presença de vômitos com reposição hipotônica quanto à secreção inapropriada de $A D H$. Por fim, outra característica da doença é a presença de urina cor de "vinho do porto", decorrente do acúmulo de porfobilina, que é produto oxidado da PBG ${ }^{15}$.

Os principais desencadeantes das crises são drogas, dentre as quais se destacam os barbitúricos, a rifampicina, o ácido valpróico e os anti-inflamatórios não hormonais. Dietas rigorosas com privação alimentar são também desencadeantes, bem como o tabaco e o álcool. Também podem deflagrar crises: infecções, cirurgias, estresse e hormônios esteroides. Finalmente, fatores endócrinos são de 
suma importância na etiologia, visto que a fase lútea do ciclo menstrual das mulheres é grande deflagrador de crises $^{1,18}$.

As crises são marcadas por aumento maciço de ALA e PBG urinários (25-100mg/d e 50-200mg/d, respectivamente). Para sua identificação, alguns testes podem ser realizados: teste de Watsom Schwartz detecta PBG urinário, é rápido e eficiente; método de coluna de Mauzerall e Granick, quantitativo e específico, detecta tanto ALA quanto PBG, e trace PBG Kit é um método semi-quantitativo ${ }^{15}$.

Para confirmação diagnóstica, é necessário determinar os níveis de PBG deaminase eritrocitária. Tal teste é limitado, pois até $10 \%$ das porfirias intermitentes agudas não cursam com redução da atividade enzimática em eritrócitos, e eritrócitos jovens tendem a ter níveis enzimáticos normais ${ }^{1}$.

O último passo diagnóstico é a detecção da mutação da PBG deaminase (tem $95 \%$ de sensibilidade e $100 \%$ de especificidade). Esse passo é importante, também, por detectar status de carreador genético'.

(b) Porfiria por deficiência da ALA desidratase (porfiria Doss/ADP)

Distúrbio raro decorrente da deficiência da ALA desidratase.

Duas situações clínicas podem causar inibição da ALA desidratase e deflagrar sintomas de porfiria: intoxicação por chumbo e tirosinemia hereditária tipo 1, que aumenta a succinilacetona, responsável pela inibição enzimática.

Clinicamente, a porfiria Doss tem manifestação muito semelhante à da porfiria intermitente aguda, cursando com crises intermitentes de paresias, dor em membros e vômitos. Laboratorialmente, observase aumento urinário de ALA e coproporfirinogênio III, além de aumento fecal deste último. Há, ainda, aumento da zinco-protoporfirina ertitrocitária1.

(c) Coproporfiria Hereditária $(\mathrm{CPH})$
Transtorno autossômico dominante, caracterizado por deficiência na coproporfirinogênio oxidase.

Cursa com sintomas muito semelhantes ao da porfiria intermitente aguda, exceto pela presença de sintomas cutâneos. Sendo assim, 89\% dos pacientes apresentam dor abdominal, 33\%, sintomas neurológicos, $28 \%$, sintomas psiquiátricos, $25 \%$, sintomas cardiovasculares e $14 \%$, sintomas cutâneos, principalmente lesões bolhosas em áreas fotoexpostas.

Laboratorialmente, há aumento de coporporfirinogênio III na urina e nas fezes. Durante as crises, há aumento também de ALA e PBG urinários.

\section{(d) Porfiria Variegata (PV)}

Distúrbio autossômico dominante caracterizado pela deficiência da protoporfirinogênio oxidade. Comum, especialmente, entre brancos na África do Sul (mutação R59W) ${ }^{1}$.

Cursa com ataques agudos similares ao da porfiria intermitente aguda, além de sintomas cutâneos. Estes são caracterizados por fragilidade cutânea, vesículas, bolhas, erosões, hiperpigmentação e hipertricose nas áreas expostas ao sol, com duração maior do que os ataques neuroviscerais ${ }^{19}$.

Laboratorialmente, há aumento de protoporfirinogênio e coproporfirinogênio fecais, além de aumento de coproporfirinogênio urinário. Durante os ataques neuroviscerais, há aumento, ainda, de ALA e PBG urinários. Fora das crises, ALA e PBG se encontram em níveis normais ou apenas discretamente aumentados ${ }^{1}$.

\section{Diagnóstico}

Os Fluxogramas 1, 2 e 3 mostram passos para diagnóstico inicial das porfirias, a partir dos sintomas clínicos apresentados pelo pacientes.

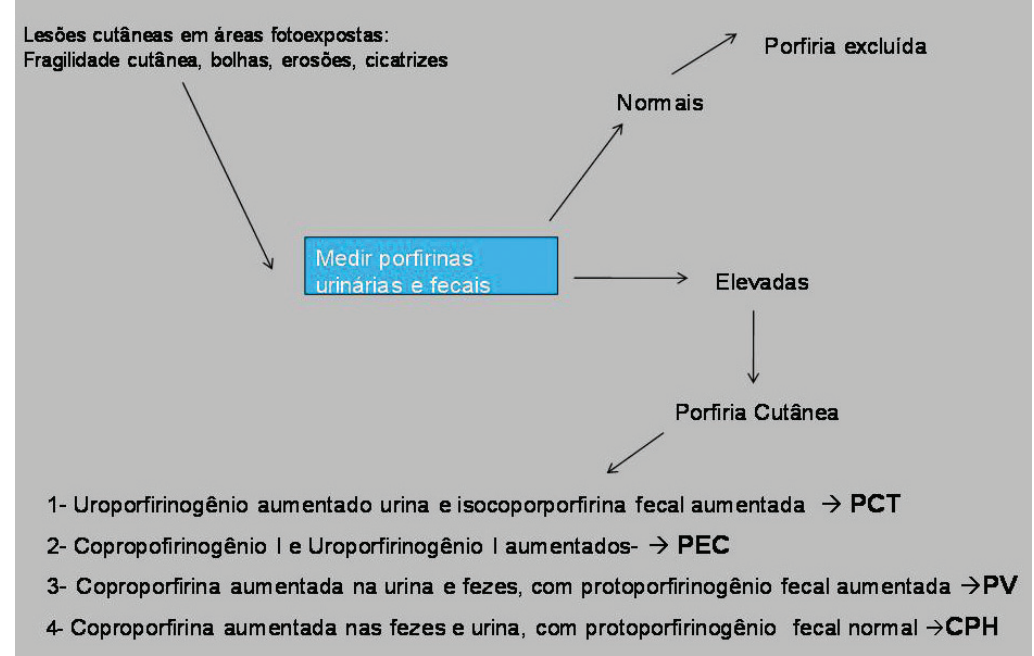

FLUXOGRAMA 1: Diagnóstico das porfirias com lesões bolhosas 


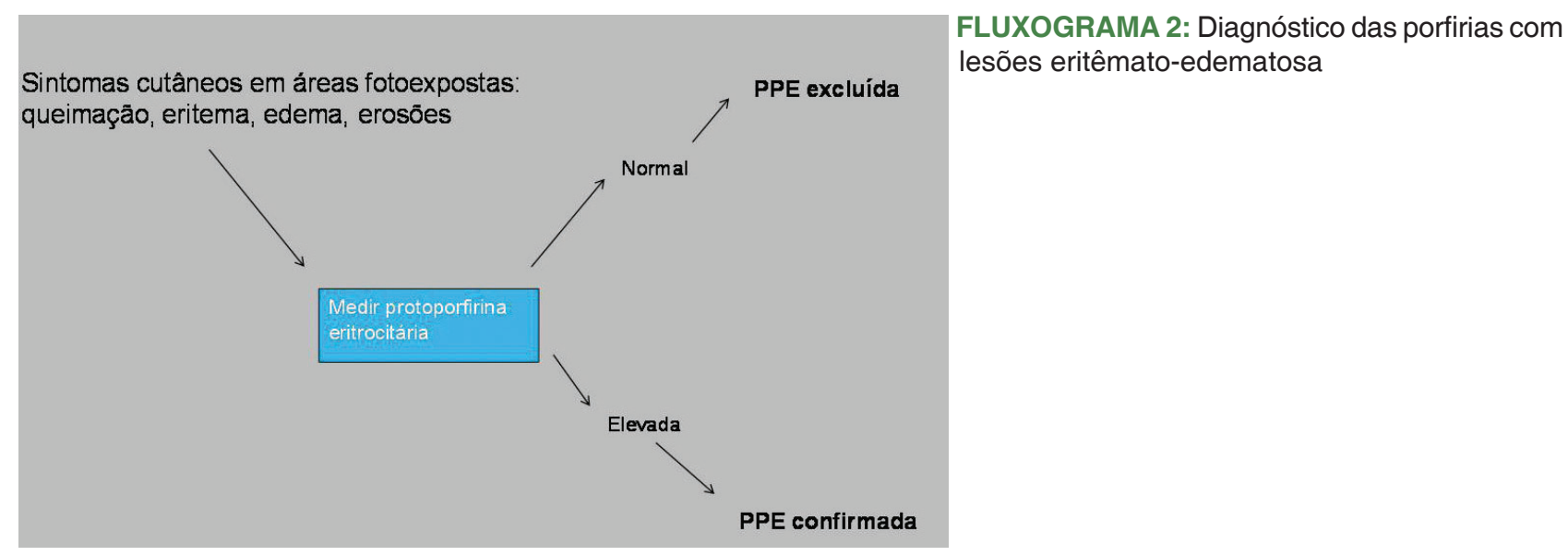

FLUXOGRAMA 3: Diagnóstico das porfirias com crises neuroviscerais

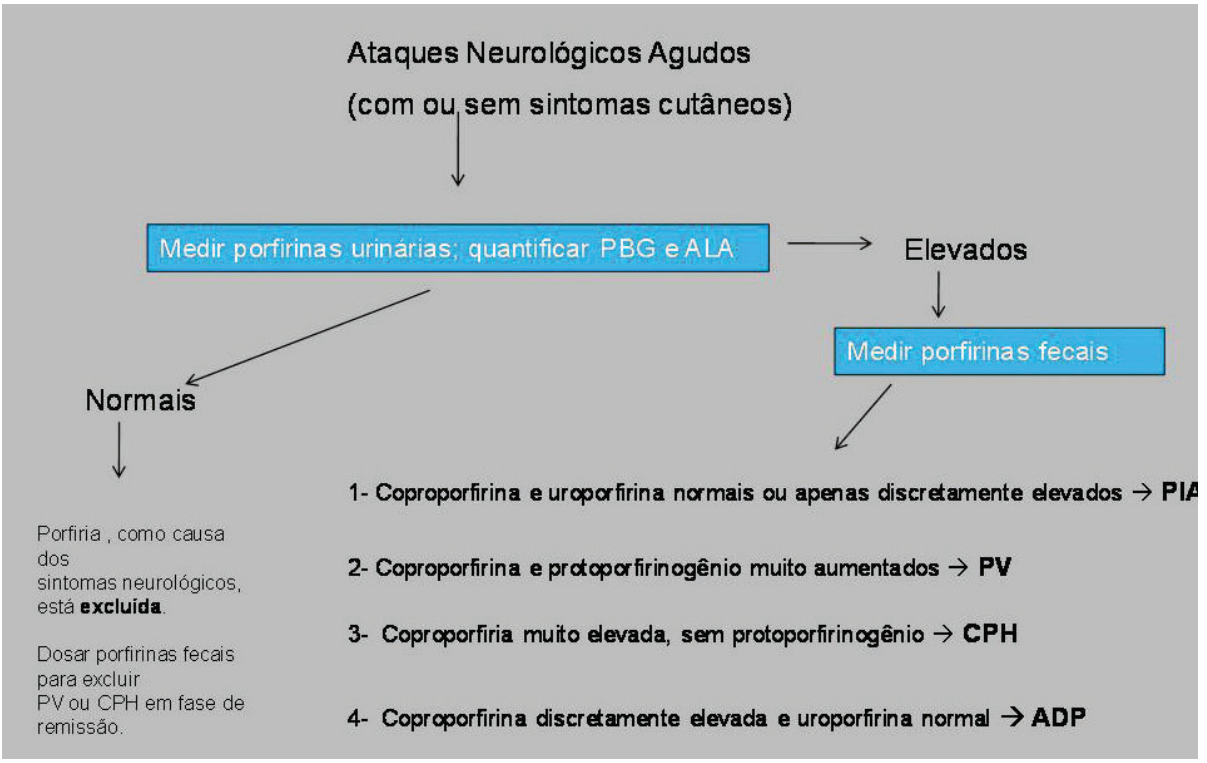

Tratamento

As Tabelas 3, 4, 5 e 6 resumem o tratamento das porfirias apresentadas.

TABELA 3: Tratamento das porfirias eritropoiéticas

\begin{tabular}{|c|c|c|}
\hline & Tratamentos convecionais & Tratamentos menos frequentes \\
\hline $\begin{array}{l}\text { Porfiria } \\
\text { Eritropoiética } \\
\text { Congênita }\end{array}$ & $\begin{array}{l}\text { - Proteção contra luz solar e exposição UV (1) } \\
\text { - Mudar ritmo dia-noite (6) } \\
\text { - Suporte transfusional (1) } \\
\text { - Esplenectomia (26) } \\
\text { - TMO alogênico (22) }\end{array}$ & $\begin{array}{l}\text { - Hidroxiuréia (20) } \\
\text { - Carvão oral (27) } \\
\text { - Infusão regular de hematina (28) } \\
\text { - Cloroquina em baixas doses (125mg 2x/semana) (6) } \\
\text { - Terapia Gênica (ainda somente em animais) (29) }\end{array}$ \\
\hline $\begin{array}{l}\text { Protoporfiria } \\
\text { Eritropoiética }\end{array}$ & $\begin{array}{l}\text { - Fotoproteção } \\
\text { - Evitar exposição solar } \\
\text { - Beta caroteno oral } 120-180 \mathrm{mg} / \mathrm{dia}(\text { nível } \\
\text { plasmático de } 600-800 \mathrm{mcg} / \mathrm{dL})(21,30)\end{array}$ & $\begin{array}{l}\text { - Colestiramina e carvão ativado (1) } \\
\text { - Transfusão de sangue e transfusão de troca (1) } \\
\text { - Hematina endovenosa para suprimir a produ-ção } \\
\text { eritróide e hepática de protoporfirinas (1) } \\
\text { - Transplante de Fígado (1) }\end{array}$ \\
\hline
\end{tabular}


Dinardo Cl, et al. Porfirias: quadro clínico, diagnóstico e tratamento.

TABELA 4: Tratamento das porfirias hepáticas crônicas

\begin{tabular}{|c|c|c|}
\hline & Tratamento convencional & Tratamentos menos frequentes \\
\hline Porfiria Cutânea Tarda & $\begin{array}{l}\text { 1- Fotoproteção } \\
\text { 2- Evitar exposição solar e trauma } \\
\text { 3- Cessar ingesta alcoólica e terapia com estrógenos } \\
\text { 4- Flebotomia: } 400-500 \mathrm{~mL} \text { cada } 2 \text { semanas por } 3-6 \\
\text { meses (31) } \\
\text { 5- Cloroquina em baixas doses: } 125 \mathrm{mg} 2 \text { } 2 \text { /semana por } \\
\text { 6-12 meses, até excreção de porfirina normal (32) }\end{array}$ & $\begin{array}{l}\text { 1- Eritropoietina Recombinante(33) } \\
\text { - IRC grave } \\
\text { - Corrige anemia, mobiliza o ferro e } \\
\text { suporta flebotomia }\end{array}$ \\
\hline Porfiria Hepatoeritropoiética & $\begin{array}{l}\text { 1- Fotoproteção } \\
\text { 2- Evitar exposição solar e trauma } \\
\text { 3- Trocar turno dia-noite } \\
\text { CUIDADO! Flebotomia e Antimaláricos são inefetivos (6) }\end{array}$ & \\
\hline
\end{tabular}

TABELA 5: Tratamento das crises das porfirias hepáticas agudas

\begin{tabular}{|c|c|}
\hline & Tratamento convencional \\
\hline $\begin{array}{l}\text { Porfiria Intermitente Aguda (porfiria } \\
\text { variegata, coproporfiria hereditária, } \\
\text { porfiria por deficiência da ALA-D) }\end{array}$ & $\begin{array}{l}\text { 1. Identificação e remoção de precipitantes (drogas, alcool, hormômios) } \\
\text { Sintomáticos } \\
\text { 2. Controle da dor } \\
\text { 3. Controle de náuseas e vômitos } \\
\text { 4. Taquicardia e hipertensão } \\
\text { 5. Convulsões } \\
\text { Tratamento específico } \\
\text { 6. Administração de carboidratos } 300 \mathrm{~g} / \text { dia } \\
\text { - Glicose e insulina juntos mais efetivos que glicose apenas (34) } \\
\text { 7. Administração de hematina } 3 \text { - } 4 \mathrm{mg} / \mathrm{Kg} 1 \text { x dia por } 4 \text { dias consecutivos (1) } \\
\text { - Reconstituir com albumina } \\
\text { - Hematina complexada com arginina é melhor (36) } \\
\text { 8. Hemodiálise (23) } \\
\text { - poucos casos } \\
\text { - opção para locais sem hematina }\end{array}$ \\
\hline
\end{tabular}

TABELA 6: Controle do intercrises das porfirias hepáticas agudas

\begin{tabular}{l|l}
\hline & Controle intercrises / seguimento \\
\hline & - Bloqueio do ciclo menstrual (35) \\
& - Infusão profilática de hematina (24) \\
\hline $\begin{array}{l}\text { Porfiria Intermitente Aguda (porfiria } \\
\text { variegata, coproporfiria hereditária, }\end{array}$ & - Mensal, semanal ou quinzenal, de acordo com as crises \\
porfiria por deficiência da ALA-D) & - Alfa feto proteína e USG de abdome a cada 6 meses \\
& - Transplante de fígado (25) \\
& - Reduz excreção de precursores de porfirina e melhora qualidade de vida \\
& - Pacientes graves \\
\hline
\end{tabular}

\section{CONCLUSÃO}

As porfirias são doenças incomuns e com herança genética na maior parte dos casos. $O$ diagnóstico das porfirias pode ser bastante difícil, dada a sobreposição de quadros clínicos e achados bioquímicos. Entretanto, o diagnóstico preciso pode muitas vezes ser feito através da dosagem das porfirinas urinárias e fecais, da análise da atividade enzimática em eritrócitos e, finalmente, da pesquisa mutacional.

O tratamento das porfirias vem evoluindo ao longo do tempo, já tendo boas experiências, em animais, de terapia gênica em porfirias eritropoiéticas. 
Dinardo CL, Fonseca GHH, Suganuma LM, Gualandro SFM, Chamone DAF. Porphyrias: clinical presentation, diagnosis and treatment. Rev Med (São Paulo). 2010 abr.-jun.;89(2):106-14.

\begin{abstract}
Porphyrias are uncommon diseases that have genetic inheritance in the majority of the cases. Porphyrias are divided in: erythropoietic porphyria, acute hepatic porphyria and chronic hepatic porphyria. The subtypes with major clinical relevance are porphyria cutanea tarda and acute intermittent porphyria. Diagnosing porphyrias may be quite difficult, as there is significant overlapping between clinical and biochemical findings. The diagnosis depends on the measurement of urinary and fecal porphyrins, enzymatic analysis of erythrocytes and, eventually, analysis of mutations. The main purpose of this article is to make a review of porphyrias, with emphasis on diagnosis and treatment of its several subtypes.
\end{abstract}

KEY WORDS: Porphyrias/diagnosis; Porphyria acute intermittent/diagnosis; Porphyria cutânea tarda/diagnosis.

\title{
REFERÊNCIAS
}

1. Sassa S. Modern diagnosis and management of the porphyrias. Br J Haematol. 2006;135, 281-92.

2. Sassa $\mathrm{S}$. The hematologic aspects of porphyria. In: Lichtman MA, Beutler E, Kipps TJ, Seligsohn U, Kaushansky K, Prchal JT, editors. Williams hematology. New York: McGraw-Hill; 2006. p. 803-22.

3. Fritsch C, Bolsen K, Ruzicka T, Goerz G. Congenital erythropoietic porphyria. J Am Acad Dermatol. 1997;36:594-610.

4. Poh-Fitzpatrick MB. Diagnosis and treatment of erythropoietic protoporphyria. Compr Ther. 1984;10:12-7.

5. Lau KC, Lam CW. Automated imaging of circulating fluorocytes for the diagnosis of erythropoietic protoporphyria: a pilot study for population screening. J Med Screen. 2008;15:199-203.

6. Poblete-Gutiérrez P, Wiederholt T, Merk HF, Frank J. The porphyrias: clinical presentation, diagnosis and treatment. Eur J Dermatol. 2006;16(3):230-40.

7. Grossman ME, Bickers DR, Poh-Fitzpatrick MB, DeLeo VA, Harber LC. Porphyria cutanea tarda: clinical features andlaboratory findings in forty patients. Am J Med. 1979;67:277-86.

8. Egger NG, Goeger DE, Payne DA, Miskovsky EP, Weinman SA, Anderson KE. Porphyria cutanea tarda: multiplicityof risk factors including HFE mutations, hepatitis $\mathrm{C}$, and inheriteduroporphyrinogen decarboxylase deficiency. Dig Dis Sci. 2002;47:41926.

9. Ho AY, Deacon A, Osborne G, Mufti GJ. Precipitation of porphyria cutanea tarda by imatinib mesylate? $\mathrm{Br} \mathrm{J}$ Haematol. 2003;121(2):375.

10. Roberts AG, Whatley SD, Morgan RR, Worwood M, Elder $\mathrm{GH}$. Increased frequency of the haemochromatosis Cys282Tyr mutation in sporadic porphyria cutanea tarda. Lancet. 1997;349:321-3.

11. Meyer UA, Schuurmans MM, Lindberg RL. Acute porphyrias:pathogenesis of neurological manifestations. Semin Liver Dis. 1998;8:43-52.
12. Mueller WE, Snyder SH. d-Aminolevulinic acid: influences on synergistic GABA receptor binding may explain CNS symptoms of porphyria. Ann Neurol. 1977;2:340-2.

13. Whetsell WOJ, Sassa S, Kappas A. Porphyrin-heme biosynthesis in organotypic cultures of mouse dorsal root ganglia. Effects of heme and lead on porphyrin synthesis and peripheral myelin. J Clin Invest. 1984;74:600-7.

14. Litman DA, Correia MA. Elevated brain tryptophan and enhanced 5-hydroxytryptamine turnover in acute hepatic heme deficiency: clinical implications. J Pharmacol Exp Ther. 1985;232:337-45.

15. Bonkovsky HL. Neurovisceral porphyrias: what a hematologist needs to know. Hematol Am Soc Hematol Educ Program. 2005:24-30.

16. Jeans JB, Savik K, Gross CR, Weimer MK, Bossenmaier IC, Pierach CA, Bloomer JR. Mortality in patients with acute intermittent porphyria requiring hospitalization: a United States case series. Am J Med Genet. 1996;65:269-73.

17. Pischik E. Neurological manifestations of acute intermittent porphyria. Cell Mol Biol (Noisy-le-grand). 2009;55(1):72-83.

18. Anderson KE, Bloomer JR, Bonkovsky HL, Kushner JP, Pierach CA, Pimstone NR, Desnick RJ. Recommendations for the diagnosis and treatment of the acute porphyries. Ann Intern Med. 2005;142(6):43950.

19. Hift RJ, Meissner PN, Todd G, Kirby P, Bilsland D, Collins $P$, et al. Homozygous variegate porphyria: an evolving clinical syndrome. Postgrad Med J. 1993;69:781-6.

20. Guarini L, Piomelli S, Poh-Fitzpatrick MB. Hydroxyurea in congenital erythropoietic porphyria. New Engl J Med. 1994;330:1091-2.

21. Minder El, Schneider-Yin X, Steurer J, Bachmann LM. A systematic review of treatment options for dermal photosensitivity in erythropoietic protoporphyria. Cell Mol Biol (Noisy-le-grand). 2009;55(1):84-97. 
22. Shaw PH, Mancini AJ, McConnell JP, Brown D, Kletzel $M$. Treatment of congenital erythropoietic porphyria in children by allogeneic stem cell transplantation: a case report and review of the literature. Bone Marrow Transplant. 2001;27:101-5.

23. Prabahar MR. Manorajan R, Sathiyakumar D, Soundararajan P, Jayakumar M. Hemodialysis: a therapeutic option for severe attacks of acute intermittent porphyria in developing countries. Hemodial Int. 2008;12(1):34-8.

24. Lamon JM, Frykholm BC, Bennett M, Tschudy DP. Prevention of acute porphyric attacks by intravenous haematin. Lancet. 1978;2:492-4.

25. Soonawalla ZF, Orug T, Badminton MN, Elder GH, Rhodes JM, Bramhall SR, et al. Liver transplantation as a cure for acute intermittent porphyria. Lancet. 2004;363:705-6.

26. Piomelli S, Poh-Fitzpatrick MB, Seaman C, Skolnick LM, Berdon WE. Complete suppression of the symptoms ofcongenital erythropoietic porphyria by long-term treatment with high-level transfusions. New Engl J Med. 1986;314:1029-31.

27. Tishler PV, Winston SH. Rapid improvement in the chemicalpathology of congenital erythropoietic porphyria with treatmentwith superactivated charcoal. Methods Find Exp Clin Pharmacol. 1990;12:645-8.

28. Rank JM, Straka JG, Weimer MK, Bossenmaier I, Taddeini BL, Bloomer JR. Hematin therapy inlate onset congenital erythropoietic porphyria. $\mathrm{Br} \mathrm{J}$ Haematol. 1990;75: 617-22.

29. Verneuil H, Robert-Richard E, Ged C, Mazurier F, Richard E, Moreau-Gaudry F. Successful gene therapy of mice with congenital erythropoietic porphyria. Med Sci (Paris). 2008;24(6-7):615-20.

30. Mathews-Roth MM, Pathak MA, Fitzpatrick TB, Harber $\mathrm{LH}$, Kass EH. Beta carotene therapy for erythropoietic protoporphyriaand other photosensitivity diseases. Arch Dermatol. 1977;113:1229-32.

31. Ippen, $\mathrm{H}$. Treatment of porphyria cutanea tarda by phlebotomy. Semin Hematol. 1977; 14:253-9.

32. Valls V, Ena J, Enriquez de Salamanca R. Low-dose oralchloroquine in patients with porphyria cutanea tarda and lowmoderateiron overload. J Dermatol Sci. 1994;7:169-75.

33. Anderson KE, Goeger DE, Carson RW, Lee SM, Stead RB. Erythropoietin for the treatment of porphyria cutanea tardain a patient on long-term hemodialysis [published erratum appearsin N Engl J Med. 1990;322(22):1616]. New Engl J Med. 1990;322:315-7.

34. Handschin C, Lin J, Rhee J, Peyer AK, Chin S, $\mathrm{Wu} \mathrm{PH}$, et al. Nutritional regulation of hepaticheme biosynthesis and porphyria through PGC-1alpha. Cell. 2005;122,505-15.

35. Anderson KE, Spitz IM, Bardin CW, Kappas A. Agonadotropin releasing hormone analogue prevents cyclical attacksof porphyria. Arch Intern Med. 1990;150:1469-74.

36. Mustajoki P, Tenhunen R, Pierach C, Volin L. Heme inthe treatment of porphyrias and hematological disorders. Semin Hematol. 1989;26:1-9.

Artigo recebido em: 26/06/2010

Artigo aceito em: 26/06/2010 
Rev Med (São Paulo). 2010 abr.-jun.;89(2):106-14. 
Dinardo Cl, et al. Porfirias: quadro clínico, diagnóstico e tratamento. 